\title{
Multicentric Reticulohistiocytosis: A Reason for Erosive Arthritis
}

Yuan Yao ${ }^{1}$, Jinjun Wang ${ }^{2}$, Bin Liu ${ }^{1,2^{*}}$, Xuan Zhang ${ }^{3}$ and Stanley M Naguwa ${ }^{2}$

${ }^{1}$ Department of Rheumatology and Immunology, The Affiliated Hospital of Medical College Qingdao University, No.16 Jiang Su Lu, Shi Nan District, Qingdao City, Shandong Province, 266003, China

2Division of Rheumatology, Allergy and Clinical Immunology, University of California, Davis, CA 95616, USA

${ }^{3}$ Department of Rheumatology, Peking Union Medical College Hospital, Chinese Academy of Medical Science, 1 Shuaifuyuan, Dongcheng District, Beijing, 100730, China

"Corresponding author: Bin Liu, Department of Rheumatology and Immunology, The Affiliated Hospital of Medical College Qingdao University, No. 16 Jiang Su Lu, Shi Nan District, Qingdao City, Shandong Province, 266003, China, Tel: 5307509827; E-mail : binliupumc@hotmail.com

Received: June 03, 2014, Accepted: June 27, 2014, Published: July 04, 2014

Copyright: ( 2014 Yao Y, et al. This is an open-access article distributed under the terms of the Creative Commons Attribution License, which permits unrestricted use, distribution, and reproduction in any medium, provided the original author and source are credited.

\begin{abstract}
Multicentric Reticulohistiocytosis (MRH) is a rare histiocytic disorder that primarily involves the skin and joints but can affect multiple visceral organs. A female patient presented a characteristic papulonodular skin eruption and polyarthritis with positive Antinuclear Antibody (ANA), and skin biopsy findings demonstrated classic features of $\mathrm{MRH}$. The patient's clinical manifestations were in remission after treatment, yet X-ray showed progressive erosions of finger joints. $\mathrm{MRH}$ is an aggressive, debilitating and disabling condition, an optimal treatment strategy is necessary performed to improve outcome.
\end{abstract}

Keywords: Multicentric reticulohistiocytosis; Erosive arthritis; Diagnosis; Therapy

\begin{abstract}
Abbreviations:
ANA: Antinuclear Antibody; CYC: Cyclophosphamide; CRP: Creative Protein; DMARDs: Disease-Modifying Antirheumatic Drugs; DIP: Distal Interphalangeal Joint; ESR: Erythrocyte Sedimentation Rate; MCP: Metacarpophalangeal Joints; MRH: Multicentric Reticulohistiocytosis; RF: Rheumatoid Factor; TB: Tuberculosis

\section{Introduction}

Multicentric Reticulohistiocytosis (MRH) is a rare multisystem granulomatous condition of unknown etiology characterized by severe destructive polyarthritis and papulonodular mucocutaneous lesions, usually seen in a fourth decade female. Patients with MRH may have constitutional symptoms of fever and weight loss. The disease also can involve bone marrow, muscle, lymph nodes and other vital organs $[1,2]$. The management of MRH is difficult and still mainly empirical but Disease-Modifying Antirheumatic Drugs (DMARDs) have been successfully utilized.
\end{abstract}

We reported a case of MRH who achieved sustained improvement of her clinical manifestations except for a destructive polyarthritis and review the literature related to $\mathrm{MRH}$.

\section{Case Report}

A 61-year-old female presented with symmetric polyarthritis involving hands, wrists, elbows, shoulders, knees and ankles, and cutaneous lesions a year ago. It was associated with repeat episodes of low grade fever and loss of appetite. Initially, skin nodules were located on paranasal areas; but six months later, subcutaneous nodules were present over elbows, periungual and dorsal surface of fingers, upper chest, scalp, upper back and neck. The patient suffered intense pruritus and there was no mucosal lesion. There was no family history of MRH or any known history of contact with Tuberculosis (TB) patients.

Tenderness and swelling of the Distal Interphalangeal Joint (DIP) and Metacarpophalangeal joints (MCP) of both hands were observed (Figure 1A). A dermatological examination revealed hundreds of pruritic papules and nodules on face, scalp, dorsal hands, proximal nail folds, upper back and extensor surface of the arms which varied in size from several millimeters to $2 \mathrm{~cm}$ and varied in color from dark reddish brown to flesh colored. The papulonodular lesions involving the paranasal region produced a "leonine faces" (Figure 1B). In addition, the nodules were scattered and isolated or grouped into a confluent mass, giving a cobblestone appearance (Figure 1C). Ulceration did not occur.

Laboratory studies revealed an Erythrocyte Sedimentation Rate (ESR) of $25.2 \mathrm{~mm} / \mathrm{hr}$, a Creative Protein (CRP) $76.67 \mathrm{mg} / \mathrm{L}$, the total cholesterol of $5.03 \mathrm{mmol} / \mathrm{L}$, with a normal complete blood cell count, urine analysis, haemoglobin and blood chemistry screen. The ANA titer was 1:1000 (nucleolar pattern), but the rheumatoid factor, antiCCP antibodies, immunoglobulins $\mathrm{A} / \mathrm{G} / \mathrm{M}$, anti-ENA antibodies and Antineutrophil Cytoplasmic Antibodies (ANCA) were negative [3]. Thyroid function tests and tumor markers were normal.

Radiography of the hands revealed marginal erosions in multiple joints including DIP (Figure 2A). A Computed Tomographic (CT) scan of the chest, transvaginal ultrasound, mammogram, and gynecologic examinations were all reported as normal. A punch biopsy of a skin lesion demonstrated a dermal nodular infiltrate composed predominantly of multinucleated histiocytes with "glassy" cytoplasm with fine periodic acid-Schiff-positive granules (Figure 3A). These cells stained diffusely with CD68 and CD163 but negative for CD1a and $\mathrm{S} 100$ protein (Figure 3B and 3C). The pathological findings in this clinical setting confirmed the diagnosis of MRH.

Her symptoms were markedly improvement after treated with Cyclophosphamide (CYC) $0.2 \mathrm{~g} / \mathrm{m}^{2}$ per week in combination with prednisone at $0.5 \mathrm{mg} / \mathrm{kg} /$ day. Three months later, the skin condition 
resolved and the pain of joints were relieved (Figure 1D, 1E). The ESR and CRP became normal. Prednisone was gradually tapered to $5 \mathrm{mg}$ once daily and CYC $0.2 \mathrm{~g} / \mathrm{m}^{2}$ continued once weekly. After 1 year treatment, she stopped all therapy on her own and symptoms did not relapse in subsequently 2 years follow-up. However, repeat radiography of the hands revealed progression of bony erosions (Figure $2 \mathrm{~B}$ ). Then the patient is taking prednisone $5 \mathrm{mg}$ once daily and CYC $0.2 \mathrm{~g} / \mathrm{m}^{2}$ once weekly.

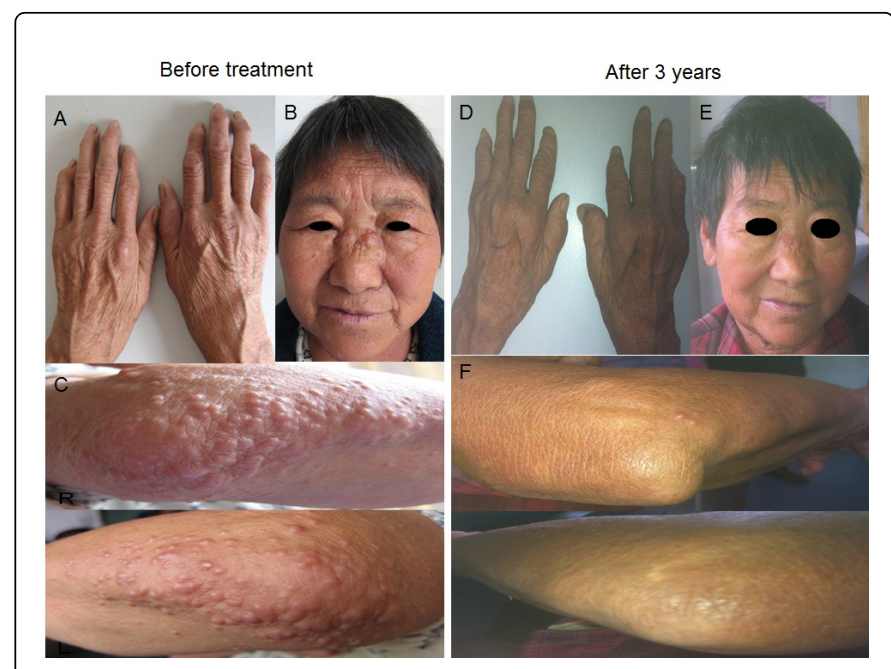

Figure 1: (A) Nodular lesions over fingers with flexion deformitites of DIP. (B) Papulonodular in the paranasal region show "leonine faces". (C) Nodules on elbow, giving a cobblestone appearance. (D, E, F) After 3 years of receiving prednisone and CYC therapies

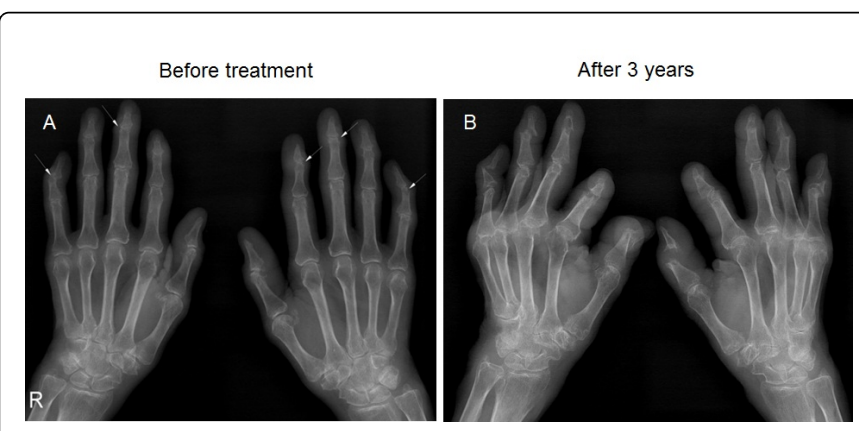

Figure 2: X-ray of the hands. (A) Osteoporosis at both ends of the two hands, irregular bone destruction on part of the DIP, narrowing of local joint spaces. (B) After 3 years, repeated X-ray showed large erosions of DIP. Note the markedly enlarged joint space and the absence of heterotrophic new bone formation.

\section{Discussion}

MRH lesions first termed by Goltz and Laymon in 1954, is characterized by an infiltrate of histiocytes and multinucleated giant cells [4-6]. The pathogenesis of MRH is unknown but a reactive inflammatory response to an underlying autoimmune, mycobacteria or malignant disorder stimulus with histiocytic proliferation is thought to occur [7]. Macrophage activation is evident with a release of inflammatory cytokines such as interleukin-12 (IL-12), IL-1b, IL-6, and tumor necrosis factor $\alpha(\mathrm{TNF}-\alpha)$ that promotes macrophage proliferation and phagocytosis, and may be involved in the disease process [8].
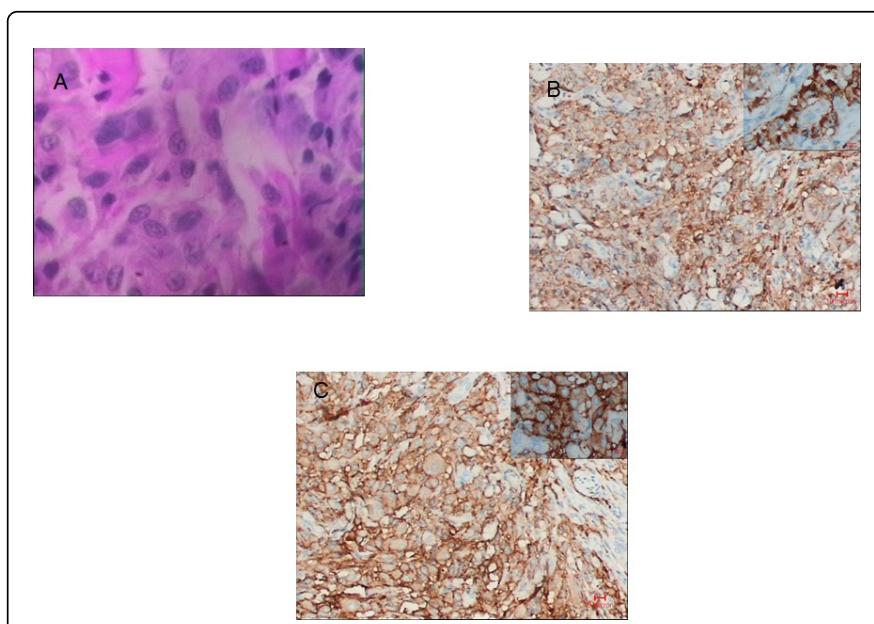

Figure 3: Histology of the skin. (A) Dermal infiltration with multinucleated giant cells with an amorphous, eosinophilic, "ground-glass"-appearing cytoplasm. (B) Positive CD68 stain. (C) Positive CD163 stain (original magnifications $\times 40$ [main] and $\times 100$ [inset])

MRH has an insidious onset and non-specific systemic manifestations. Most of patients present with skin and joint symptoms; visceral lesions are uncommon [2,9-11]. The skin lesions are characterized by flesh-colored to reddish-brown papules and nodules, most commonly scattered and isolated or grouped located on the face and hands with a predilection for the periungeal area giving a characteristic coral bed and cobblestone appearance. Severe involvement in the paranasal region, as in our patient, can produce a leonine faces [12]. Xanthelasma occurs in about one third of patients. Mucosal surfaces on the lips, tongue, buccal, pharyngeal, gingival, and nasal septum are involved in over half of the cases. Cutaneous and mucosal lesions always recur and remit spontaneously or with therapy [5]. The polyarthritis mimics severe Rheumatoid Arthritis (RA), and affects $\sim 75 \%$ of the patients with MRH. It is symmetric, diffuse, progressive and mutilating arthritis, commonly involving the DIP joints of the hands [13]. The disabling arthritic process evolves speedily in the early stage and then reduces in intensity to over the ensuing 8 to 10 years [14].

Radiography is an important tool in the diagnosis of $\mathrm{MRH}$ and also helps distinguish MRH from other causes of erosive arthritis. Imaging studies demonstrate erosions which advance from the joint margins to involve the entire joint surface and result in a widening of the joint space, loss of cartilage, and resorption of subchondral bone without osteopenia and periosteal new bone formation, which is different from other forms of inflammatory arthritis [15]. The rapidly progressive arthritis results in the characteristic opera glass hand deformity. Arthritis of the wrists and feet with erosion and joint space narrowing can sometimes be seen $[16,17]$.

There are no specific laboratory tests for diagnosing MRH. An elevated ESR and anemia are seen in about half of the patients. About one third of patients may have hyperlipidemia. A positive RF and ANAas well as hypergammaglobulinemiahave been noted only rarely. Synovial fluid analysis has been performed on a few patients without 
characteristic findings [16]. Our patient had raised ESR, CRP, serum lipid and positive ANA without malignancy.

The diagnosis of MRH is established on the basis of histopathologic features of nodules in skin or synovial tissue. The typical infiltrate is composed of many mononuclear histiocytes with multinucleated foreign body-type giant cells with ground glass appearing eosinophilic cytoplasm containing large amounts of periodic acid Schiff positive material. CD68 seems to be constant and reliable marker identified in the large mononucleate cells of MRH $[8,16]$.

MRH has been described in association with internal malignancy or connective tissue disease $[5,7,8]$. Some authors indicate $\mathrm{MRH}$ as a paraneoplastic syndrome in up to $25 \%$ patients, but causal the relationship between MRH and malignancy cannot be verified [18-20]. The differential diagnosis of MRH must include all other causes of erosive polyarthritis such as RA, Psoriatic Arthritis (PA) and gout. $\mathrm{MRH}$ also needs to be differentiated from other diseases that present with mucocutaneous lesions and erosive arthritis, for instance sarcoidosis, lepromatous leprosy and histiocytosis X. In all these conditions other typical systemic features may help to differentiate them from MRH. Tissue biopsy is recommended and X-ray may be crucial in making an early diagnosis especially because arthritis may precede all other symptoms of MRH [21].

Owing to the rarity of the disease and the unfeasibility of controlled trials, a consensus treatment of MRH has not yet been established and remains largely empirical. A striking improvement in symptoms has been demonstrated with methotrexate, CYC and chlorambucil when used alone or in combination with corticosteroids. Unfortunately, remission has been achieved only rarely [13,18]. Recently, cyclosporine, anti-TNF- $\alpha$ agents, tocilizumab, leflunomide and alendronate have been tried and appear to offer other effective therapeutic options [22-26]. Prior to initiating aggressive therapy, screening of malignancy and TB should be performed. Treatment of the primary malignancy has achieved complete remission of MRH in many cases. In addition, the use of immunosuppressants is contraindicated in patients with active $\mathrm{TB}$, and treatment of active TB has also induced partial remission from $\mathrm{MRH}$.

Our patient was diagnosed as MRH according to clinical manifestations, histological findings and X-ray. Systemic treatment with prednisone $40 \mathrm{mg}$ once daily and CYC $0.2 \mathrm{~g} / \mathrm{m}^{2}$ once weekly was commenced. Three months later, skin signs had cleared to a slight erythema of the scalp only and joint symptoms rapidly improved. Prednisone was gradually tapered to $5 \mathrm{mg}$ once daily and CYC 0.2 $\mathrm{g} / \mathrm{m}^{2}$ continued once weekly. After 1 year treatment, she stopped all therapy and symptoms did not relapse in subsequently 2 years followup. However, repeat radiography of the hands revealed progressive bony erosions. Although some patients of MRH have a self-limiting course of disease, most of MRH could cause destructive arthritis and disfiguring $[15,16]$. Our patient developed an irreversible deforming arthritis even though the skin lesions have subsided. Therefore, it is recommended that the disease be treated very aggressively. CYC $(0.2$ $\mathrm{g} / \mathrm{m}^{2}$ once weekly) in combination with corticosteroids has provided our patient for remission from $\mathrm{MRH}$.

In recent years, the prognosis for $\mathrm{MRH}$ has improved, possibly benefit from earlier diagnosis and/or more aggressive therapy. Although MRH is uncommon disease, this condition can result in irreversible arthritis mutilans and disfigurement of the faces. Therefore, it is important that there be early recognition and management of this disease to prevent disability.

\section{Acknowledgement}

Supported by grants from Natural Sciences Foundation of China (No.81241094) and Science and Technology program of basic research projects of Qingdao city (NO.13-1-4-138-jch)

\section{References}

1. Yee KC, Bowker CM, Tan CY, Palmer RG (1993) Cardiac and systemic complications in multicentric reticulohistiocytosis. Clin Exp Dermatol 18: 555-558.

2. Webb-Detiege T, Sasken H, Kaur P (2009) Infiltration of histiocytes and multinucleated giant cells in the myocardium of a patient with multicentric reticulohistiocytosis. J Clin Rheumatol 15: 25-26.

3. Lutz H, Trautwein C, Tischendorf JW (2013) Primary sclerosing cholangitis: diagnosis and treatment. Dtsch Arztebl Int 110: 867-874.

4. GOLTZ RW, LAYMON CW (1954) Multicentric reticulohistiocytosis of the skin and synovia; reticulohistiocytoma or ganglioneuroma. AMA Arch Derm Syphilol 69: 717-731.

5. Barrow MV, Holubar K (1969) Multicentric reticulohistiocytosis. A review of 33 patients. Medicine (Baltimore) 48: 287-305.

6. M. Tandy Sutton, Laurie Massa (2009) A progressive rash and fatigue. Journal of the American Academy of Dermatology 60: 893-895.

7. Campbell DA, Edwards NL (1991) Multicentric reticulohistiocytosis: systemic macrophage disorder. Baillieres Clin Rheumatol 5: 301-319.

8. Gorman JD, Danning C, Schumacher HR, Klippel JH, Davis JC Jr (2000) Multicentric reticulohistiocytosis: case report with immunohistochemical analysis and literature review. Arthritis Rheum 43: 930-938.

9. Roth S, Campagni JP, Perrin C, Sanderson F, Castela J, et al. (2006) [Paraneoplasic multicentric reticulohistiocytosis associated with a celiac disease]. Rev Med Interne 27: 263-265.

10. Benucci M, Sulla A, Manfredi M (2008) Cardiac engagement in multicentric reticulohistiocytosis: report of a case with fatal outcome and literature review. Intern Emerg Med 3: 165-168.

11. Yang HJ, Ding YQ, Deng YJ (2009) Multicentric reticulohistiocytosis with lungs and liver involved. Clin Exp Dermatol 34: 183-185.

12. Tajirian AL, Malik MK, Robinson-Bostom L, Lally EV (2006) Multicentric reticulohistiocytosis. Clin Dermatol 24: 486-492.

13. Liang GC, Granston AS (1996) Complete remission of multicentric reticulohistiocytosis with combination therapy of steroid, cyclophosphamide, and low-dose pulse methotrexate. Case report, review of the literature, and proposal for treatment. Arthritis Rheum 39:171-174.

14. Lesher JL Jr, Allen BS (1984) Multicentric reticulohistiocytosis. J Am Acad Dermatol 11: 713-723.

15. Islam AD, Naguwa SM, Cheema GS, Hunter JC, Gershwin ME (2013) Multicentric reticulohistiocytosis: a rare yet challenging disease. Clin Rev Allergy Immunol 45: 281-289.

16. Trotta F, Castellino G, Lo Monaco A (2004) Multicentric reticulohistiocytosis. Best Pract Res Clin Rheumatol 18: 759-772.

17. Uhl M, Gutfleisch J, Röther E, Langer M (1996) Multicentric reticulohistiocytosis. A report of 3 cases and review of literature. Bildgebung 63: 126-129.

18. Luz FB, Gaspar TAP, Kalil-Gaspar N, Ramos-e-Silva M (2001) Multicentric reticulohistiocytosis. J Eur Acad Dermatol Venereol 15: 524-531.

19. Kishikawa T, Miyashita T, Fujiwara E, Shimomura O, Yasuhi I, et al. (2007) Multicentric reticulohistiocytosis associated with ovarian cancer. Mod Rheumatol 17: 422-425.

20. Hinchman KF, Wu JJ, Soden CE Jr, Waldman J, Dyson SW (2008) Multicentric reticulohistiocytosis associated with Burkitt lymphoma and adenocarcinoma. Cutis 82: 113-114.

21. Levin J, Werth VP (2006) Skin disorders with arthritis. Best Pract Res Clin Rheumatol 20: 809-826.

22. Goto H, Inaba M, Kobayashi K, Imanishi $Y$, Kumeda $Y$, et al. (2003) Successful treatment of multicentric reticulohistiocytosis with 
Citation: Yao Y, Wang J, Liu B, Zhang X, Naguwa SM (2014) Multicentric Reticulohistiocytosis: A Reason for Erosive Arthritis. J Diabetes Metab 5: 400. doi:10.4172/2155-6156.1000400

Page 4 of 4

alendronate: evidence for a direct effect of bisphosphonate on histiocytes. Arthritis Rheum 48: 3538-3541.

23. Chalom EC, Rosenstein ED, Kramer N (2000) Cyclosporine as a treatment for multicentric reticulohistiocytosis. J Rheumatol 27: 556.

24. Matejicka C, Morgan GJ, Schlegelmilch JG (2003) Multicentric reticulohistiocytosis treated successfully with an anti-tumor necrosis factor agent: comment on the article by Gorman et al. Arthritis Rheum 48: 864-866.
25. Lonsdale-Eccles AA, Haworth AE, McCrae FC, Young-Min SA (2009) Successful treatment of multicentric reticulohistiocytosis with leflunomide. Br J Dermatol 161: 470-472.

26. Pacheco-Tena C, Reyes-Cordero G, Ochoa-Albíztegui R, Ríos-Barrera V, González-Chávez SA (2013) Treatment of multicentric reticulohistiocytosis with tocilizumab. J Clin Rheumatol 19: 272-276. 